\title{
Violence against children and intimate partner violence against women: overlap and common contributing factors among caregiver-adolescent dyads
}

Catherine Carlson ${ }^{1 *}$ D, Sophie Namy ${ }^{2}$, Andrea Norcini Pala ${ }^{3}$, Milton L. Wainberg ${ }^{4}$, Lori Michau ${ }^{2}$, Janet Nakuti Louise Knight ${ }^{5}$, Elizabeth Allen ${ }^{5}$, Carin Ikenberg ${ }^{1}$, Dipak Naker $^{2}$ and Karen Devries ${ }^{5}$

\begin{abstract}
Background: Intimate partner violence against women (IPV) and violence against children (VAC) are both global epidemics with long-term health consequences. The vast majority of research to date focuses on either IPV or VAC, however the intersections between these types of violence are a growing area of global attention. A significant need exists for empirical research on the overlap of IPV and VAC, especially in contexts with particularly high rates of both types of violence.

Methods: This exploratory study includes secondary analysis of data from a cluster randomized controlled trial in Ugandan schools. Using baseline reports from a random sample of early adolescents attending school and their caregivers, this study uses a probability sample across all eligible schools of adolescent-caregiver dyads ( $n=535)$. We categorized adolescent-caregiver dyads into four groups: those reporting VAC 'only', IPV 'only', both VAC and IPV, or 'no violence'. Two separate multinomial logistic regression models for male and female caregivers explored adolescent and caregiver characteristics associated with the VAC 'only', the IPV 'only', or the both VAC and IPV dyads, each compared to the 'no violence' dyad.

Results: One third of dyads reported both IPV and VAC and nearly $75 \%$ of dyads reported VAC or IPV. Dyads reporting IPV were more likely to also report VAC. Common contributing factors for female caregiver-adolescent dyads with both VAC and IPV include lower SES, less caregiver education, higher caregiver mental distress, more frequent caregiver alcohol use, and caregivers who report less emotional attachment to their intimate partner. Male caregiver-adolescent dyads with both VAC and IPV included caregivers with less emotional attachment to their intimate partner and more attitudes accepting VAC.

Conclusions: Findings reveal a significant overlap of IPV and VAC and the importance for violence prevention and response programming to consider coordinated or integrated programming. Unique results for female and male caregivers highlight the importance of a gendered approach to addressing IPV and VAC intersections.
\end{abstract}

Trial registration: The trial was registered at clinicaltrials.gov, NCT01678846, on September 5, 2012.

Keywords: Child maltreatment, Gender-based violence, Family, Adolescence, Africa

\footnotetext{
* Correspondence: ccarlson5@ua.edu

1 University of Alabama, School of Social Work, 3026 Little Hall, Box 870314,

Tuscaloosa, AL 35487-0314, USA

Full list of author information is available at the end of the article
}

(c) The Author(s). 2020 Open Access This article is distributed under the terms of the Creative Commons Attribution 4.0 International License (http://creativecommons.org/licenses/by/4.0/), which permits unrestricted use, distribution, and reproduction in any medium, provided you give appropriate credit to the original author(s) and the source, provide a link to the Creative Commons license, and indicate if changes were made. The Creative Commons Public Domain Dedication waiver (http://creativecommons.org/publicdomain/zero/1.0/) applies to the data made available in this article, unless otherwise stated. 


\section{Background}

Intimate partner violence against women (IPV) and violence against children (VAC) by caregivers are each global epidemics $[1,2]$ with long-term health consequences $[3,4]$. The intersection of IPV and VAC is a growing area of global attention, with calls to explore integrated programming [5-7]. Yet, the vast majority of research and practice have focused on women and children separately $[5,8]$, with few empirical studies on the connection or intersection of the two types of violence. Studies that do exist are primarily from high income countries and report that IPV and VAC often occur within the same families [9-23] and neighborhoods [24], increasing risk of negative health effects [4, 17, 25-30].

A lack of evidence exists on the overlap of IPV and VAC using data from low- and middle-income countries, where higher rates of poverty and differing gender structures may have unique effects on intersecting violence in families. A study using a non-probability sample from a South African hospital [31] chart files reported a $47 \%$ rate of co-occurring IPV and VAC. Studies from Nigeria and Northern Uganda found that mothers who reported IPV were significantly more likely to also report child cruelty [32] or aggressive parenting [33]. The etiology of both IPV and VAC can be understood within an ecological framework [34, 35], where factors across multiple spheres of life drive the co-occurrence of violence. At an interpersonal level, social information processing conceptualizes the use of both types of violence due to attitudes accepting the use of violence in close relationships [36]. Intersecting violence may also be considered from a social disorganization theory perspective, where concentrated neighborhood disadvantage contributes to the occurrence of both IPV and VAC [24]. Other recent studies on intersecting IPV and VAC drawn upon a feminist framework, which contextualizes family violence and attitudes accepting violence in personal relationships within broader gender and power hierarchies $[37,38]$. A qualitative study on the intersections of IPV and VAC in Uganda explores the use of violence against both women and children as a mechanism of enforcing power hierarchies and gender/childhood norms within families [37]. In-depth interviews in South Africa, revealed that even mothers' homicidal violence against their children frequently occurred within a context of the women's long-term exposure to IPV [38]. Both of these studies reveal women's use of violence against children as their exercise of power over children, when unable to express power over their male partners.

Despite qualitative evidence on intersecting violence against women and children from Africa, a lack of research exists estimating the rates of overlapping violence in families particularly child and caregiver reports. Research from the independent VAC and IPV literature report several common factors that increase the risk of both types of violence [39, 40], such as substance abuse, mental health problems, or women and child rights [16, 41-46]. Before the development of effective, integrated programming, there is a need to better understand the overlap of IPV and VAC and shared contributing factors.

\section{Methods}

\section{Data source}

This exploratory study aims to understand shared and distinct factors across caregiver-adolescent 'dyads' experiencing no violence, IPV 'only', VAC 'only,' and overlapping IPV and VAC. Secondary analyses are performed using data from the Good Schools Study [47, 48], a cluster randomized controlled trial conducted between 2012 and 2014 to test the impact of Good School Toolkit (GST; www.raisingvoices.org). The cross-sectional follow-up survey included a probability sample of primary school students and caregivers from 42 eligible schools in Luwero District (half of which-21-had received the 18 month GST intervention). Participants were selected in two stages. After excluding 97 schools with fewer than 40 Primary 5 students and 20 additional schools with ongoing interventions in progress, 42 schools (representing $80 \%$ of students in the district) were randomly selected from a list of the 151 remaining schools in the district. A maximum of 130 students from Primary 5, 6 and 7 were randomly selected from each school (response rate 92.3\%). Any caregiver (primary or other) of all grade 7 students were also invited to complete a survey (response rate 66\%). A total of 828 adolescent and caregiver dyads completed surveys. For the purposes of these analyses, caregivers who were not currently partnered were excluded $(n=287)$, as well as caregivers for whose sex was not recorded or able to determine $(n=6)$. After these exclusions, a total of 535 adolescent-caregiver dyads were included in the secondary analyses. All surveys were administered face-to-face in the school using tablet computers by trained interviewers between June and July 2014. Caregivers were informed about the study and could opt their adolescent out from participating, and informed written consent was obtained from all students and caregivers. Any disclosure of serious maltreatment were referred to local child protection services and all children were offered counselling regarding of what they disclosed. Women reporting experiencing IPV were offered information and support in accessing domestic violence services [49]. Ethical approval was obtained from the Ugandan National Council for Science and Technology (SS 2520) and the Ethics Committee of the London School of Hygiene and Tropical Medicine (\#6183). The study followed international ethical guidelines for researching violence against women and children 
$[50,51]$, and a full discussion of the ethical protocol for the parent study is published elsewhere [49].

\section{Measures}

Measures used for the study came from cross sectional surveys with both adolescents and caregivers. All instruments were translated into Luganda. Cognitive interviewing and pre-testing of measures were carried out prior to use [52]. Interviews were conducted in Luganda or English. Demographic questions captured from caregivers and adolescents included age and sex. Caregivers reports also included their education status, religious affiliation, number of years with their intimate partner, and if they currently lived together. Adolescents reported if they currently live with one, two, or no biological parents. Table 1 describes the variables and measures used for adolescents and caregivers.

\section{Socioeconomic status (SES)}

Confirmatory factor analysis (CFA) was performed to test the 1-latent factor "SES" (items are listed in Appen$\operatorname{dix}$ A). Weighted Least Square with adjusted Mean and Variance (WLSMV) estimation was used to analyze SES items, which consisted of binary or ordinal variables [53]. The model goodness-of-fit was evaluated with the Root Mean Square Error of Approximation (RMSEA) ( $\leq .08$ or .05), and Comparative Fit Index (CFI) and Tucker-Lewis index (TLI) ( $\geq .95$ or .90) [53-56]. The 1factor model showed poor fit: $\mathrm{RMSEA}=.10$ and CFI/
TLI $=.76 / .71$. The exclusion of items with nonsignificant loadings $(p>.05)$ improved the fit of the model: RMSEA $=.05$, CFI/TLI .97/.96. The latent factor's (standardized) score was exported and used as a measure of SES, a higher score indicates higher SES. Reliability for SES and other measures was assessed with Ordinal alpha, which outperforms Cronbach's alpha when ordinal variables are analyzed [57]. $\mathrm{R}$ and psych package (Revelle, 2013) was used to compute Ordinal alpha; coefficients higher than 0.70 indicate good reliability.

\section{Physical disability}

Adolescents were asked questions on physical disability from the Washington Group short set. A dummy variable was created to measure if respondents reported any functional impairment, compared to no impairment.

\section{Mental distress}

The 20-item Self-Report Questionnaire (SRQ) [58] assessed caregiver's symptoms of mental distress. Scores range from 0 to 20 with higher numbers indicating more distress (Ordinal Alpha =0.9). The Strengths and Difficulties Questionnaire (SDQ) measured child reports of symptoms of common childhood and adolescent mental disorders, including depression, anxiety, and conduct disorder [59]. Scores range from 0 to 40 with higher numbers indicating more symptoms (Ordinal Alpha $=0.8$ ).

Table 1 Caregiver and adolescent variables and measures

\begin{tabular}{|c|c|c|}
\hline & Adolescent Report & Caregiver Report \\
\hline Age & Years & Years \\
\hline Sex & Girl, Boy & Man, Woman \\
\hline Education & & Primary vs. Secondary or more \\
\hline Religious affiliation & & Christian or Muslim \\
\hline Relationship duration & & Years with current partner \\
\hline Living status & Lives with biological parent $(\mathrm{Y} / \mathrm{N})$ & Lives with current partner $(\mathrm{Y} / \mathrm{N})$ \\
\hline Household size & & Number of persons in household \\
\hline SES & & Index (See Attachment) \\
\hline Physical Disability & $\begin{array}{l}\text { Difficulty performing any basic } \\
\text { universal tasks (Washington Group Short Set) }\end{array}$ & \\
\hline Mental distress & Strengths and Difficulties Questionnaire (alpha $=.82$ ) & Self-Report Questionnaire (alpha = .92) \\
\hline Alcohol Use & & Alcohol use frequency in past 30 days \\
\hline Relationship quality & Family connectedness (alpha $=.72$ ) & $\begin{array}{l}\text { Emotional attachment (Relationship } \\
\text { Structure Questionnaire; alpha =.90) }\end{array}$ \\
\hline Attitudes towards violence & & Attitudes against VAC (alpha $=.82)$ \\
\hline Violence & & $\begin{array}{l}\text { Emotional or physical violence against } \\
\text { children (IPSCAN) } \\
\text { Emotional, physical, or sexual violence } \\
\text { (WHO Women's Health and Life Events Questionnaire) }\end{array}$ \\
\hline Intervention & & $\begin{array}{l}\text { Adolescent attends either an intervention or } \\
\text { control school in the parent study }\end{array}$ \\
\hline
\end{tabular}




\section{Alcohol use}

Caregivers were asked the number of days that they drank alcohol in the last 30 days. Response categories ranged from 0 to 6 and the measure was treated as a continuous variable $(0,1-2,3-5,6-9,10-19,20-29$, or all 30 days).

\section{Relationship quality}

Questions on feelings of family connectedness were adapted from commonly used scales in adolescent health behavior surveys [60]. Adolescents were asked the frequency with which they "feel like my parents/caregivers care about me"; "feel safe at home"; "belong at home"; and "like to spend time at home". Scores ranged from 0 to 12 with higher numbers indicating more connectedness (Ordinal Alpha $=0.72$ ). The nine-item Relationship Structure Questionnaire [61] assessed the quality of caregivers' emotional attachment with their intimate partner, scores ranged from 0 to 27 with higher numbers indicating positive attachment (Ordinal Alpha $=0.9$ ).

\section{Attitudes towards violence}

Caregivers were rated on their agreement with the following statements: Parents must be in control of children at all times; sometimes parents must hit children to make them listen; children who misbehave should be physically disciplined; children should often fear their parents; sometimes physically disciplining children is the only way to make them respect you; and sometimes parents must hit children to make them learn. The scale, developed for the Good School Study, ranged in scores from 0 to 18 , with higher scores indicating less acceptance of violence (Ordinal Alpha $=0.8$ ).

\section{Violence}

The WHO Women's Health and Life Events Questionnaire assessed if caregivers have ever experienced (women) or perpetrated (men) any emotional, physical, or sexually violent behaviors in their current intimate relationship. Included in the questionnaire are seven different acts of violence, for example: "Slapped, pushed, or shoved you?"; "Hit you with a fist or object that could hurt you, kicked, dragged, or beat you up?"; and "Did they ever force you to have sex with them when you did not want to?" The International Society for the Prevention of Child Abuse and Neglect Screening Tool (ICAST) [62] examined caregiver's perpetration or adolescents' experiences of any physical or emotional violence against the adolescent in the dyad. In the questionnaire, participants were asked about their experiences (adolescents) or perpetration (caregivers) of eight acts of violence such as "Insulted them, or called them rude or hurtful names?"; "Twisted their arm or any other body part, slapped them, pushed them or thrown something at them?"; "Cut them with a sharp object or burnt them?" Since adolescent reports could not be attributed to the specific caregiver in the dyad, caregiver reports of perpetrating violence were used in the analyses.

\section{Intervention}

Describes whether adolescents were enrolled in an intervention or control school during the original cluster randomized controlled trial.

\section{Data analysis plan}

Descriptive analysis included mean and standard deviation (SD) for continuous variables; count and proportion (\%) for categorical variables; median and range for ordinal variables. Association between binary or nominal variables was tested with cross tab and $x^{2}$ test. Group comparison was performed using ANOVA and KruskallWallis non-parametric test for continuous and ordinal variables, respectively. Analyses were performed with SPSS and Mplus 7.4 [53].

The main outcome of the study identifies 4 types of adolescent-caregiver dyads, using caregiver reports of ever any violence: (0) No violence [1]; IPV 'only' [2]; VAC 'only' [3]; both IPV-VAC. Given the gendered nature of violence against women (and that men reported IPV perpetration whereas women reported on IPV victimization) the sample was separated by caregiver sex. Two multinomial logistic regressions (one for female caregivers and one for male) were performed to test the difference between the dyads with no violence $(0$ - reference group) and the other three types of dyads [1-3]. This statistical approach identifies variables that discriminate between the reference group and the remaining dyads performing three pairwise comparisons (i.e. 0 vs.1; 0 vs. 2 ; and 0 vs. 3 ). We reported odds-ratio and confidence intervals (CIs). Estimates with $p$ values $\leq .05$ were considered statistically significant, values $\leq .10$ were considered as statistical trends [63, 64].

We imputed missing data using Markov Chain Monte Carlo approach with $N=200$ imputations (See Appendix B). Maximum Likelihood with Robust standard error (MLR) estimation was used, to account for potential outliers and non-normal distribution [53]. Multinomial logistic regressions were adjusted for intra-class (schools) correlation. Given that this study is a secondary analysis of trial data, no formal power calculations were carried out for this study. However, the main trial was powered to detect a difference of $13 \%$ in the primary outcome (past-week physical violence from school staff) with a $5 \%$ level of significance and $80 \%$ power $[47,52]$. 
Table 2 Bivariate analysis of covariates with male caregiver-adolescent dyads

\begin{tabular}{|c|c|c|c|c|c|}
\hline & None & IPV 'Only' & VAC 'Only' & IPV and VAC & $p$ \\
\hline & $n=66$ & $n=20$ & $n=67$ & $n=51$ & \\
\hline \multicolumn{6}{|l|}{ Caregiver Report } \\
\hline Age, mean (SD) & $49.68(14.42)$ & $45.35(9.78)$ & $44.22(11.27)$ & $45.69(9.62)$ & 0.06 \\
\hline \multicolumn{6}{|l|}{ Education, \% (n) } \\
\hline Primary & $68.75(44)$ & $66.67(12)$ & $73.85(48)$ & $80.39(41)$ & \multirow[t]{2}{*}{0.49} \\
\hline High School or more & $31.25(20)$ & $33.33(6)$ & $26.15(17)$ & $19.61(10)$ & \\
\hline \multicolumn{6}{|l|}{ Religion, \% (n) } \\
\hline Catholic/Christian & $84.85(56)$ & $75(15)$ & $79.1(53)$ & $78.43(40)$ & \multirow[t]{2}{*}{0.71} \\
\hline Muslim & $15.15(10)$ & $25(5)$ & $20.9(14)$ & $21.57(11)$ & \\
\hline SES, mean (SD) & $-0.06(0.24)$ & $0.06(0.27)$ & $0(0.22)$ & $0(0.27)$ & 0.28 \\
\hline Mental distress (SRQ), mean (SD) & $3.97(3.71)$ & $5.45(4.36)$ & $5.07(3.73)$ & $6.43(3.96)$ & 0.01 \\
\hline Alcohol, median (min-max) & $0(0-5)$ & $0(0-6)$ & $0(0-6)$ & $0(0-6)$ & 0.10 \\
\hline \multicolumn{6}{|l|}{ Partner Living Status, \% (n) } \\
\hline Do not live together & $6.06(4)$ & $5(1)$ & $4.48(3)$ & $1.96(1)$ & \multirow[t]{2}{*}{0.76} \\
\hline Live together & $93.94(62)$ & $95(19)$ & $95.52(64)$ & $98.04(50)$ & \\
\hline Intimate Partner Emotional Attachment, mean (SD) & $15.38(3.17)$ & $14.68(3.02)$ & $14.66(3.12)$ & $13.86(2.41)$ & 0.07 \\
\hline Attitudes toward VAC, mean (SD) & $12(3.16)$ & $14.25(3.37)$ & $12.66(3.78)$ & $15.39(4.2)$ & 0.00 \\
\hline \multicolumn{6}{|l|}{ Adolescent Report } \\
\hline \multicolumn{6}{|l|}{ Sex, \% (n) } \\
\hline Female & $40.91(27)$ & $50(10)$ & $61.19(41)$ & $43.14(22)$ & \multirow[t]{2}{*}{0.09} \\
\hline Male & $59.09(39)$ & $50(10)$ & $38.81(26)$ & $56.86(29)$ & \\
\hline Children age, mean (SD) & $14.08(1.21)$ & $14.5(1.28)$ & $13.99(1.24)$ & $14.35(0.98)$ & 0.18 \\
\hline \multicolumn{6}{|l|}{ Physical disability, \% (n) } \\
\hline No & $75.76(50)$ & $85(17)$ & $83.58(56)$ & $82.35(42)$ & \multirow[t]{2}{*}{0.63} \\
\hline Yes & $24.24(16)$ & $15(3)$ & $16.42(11)$ & $17.65(9)$ & \\
\hline \multicolumn{6}{|l|}{ Family Structure, \% (n) } \\
\hline Lives with bio mother & $31.82(21)$ & $35(7)$ & $25.37(17)$ & $31.37(16)$ & \multirow[t]{4}{*}{0.96} \\
\hline Lives with bio father & $9.09(6)$ & $10(2)$ & $5.97(4)$ & $7.84(4)$ & \\
\hline Lives with both bio parents & $27.27(18)$ & $25(5)$ & $38.81(26)$ & $31.37(16)$ & \\
\hline Lives with neither bio parent & $31.82(21)$ & $30(6)$ & $29.85(20)$ & $29.41(15)$ & \\
\hline Mental health difficulties (SDQ), mean (SD) & $14.58(5.05)$ & $14.91(5.62)$ & $14.88(5.18)$ & $14.28(5.01)$ & 0.711 \\
\hline Belong, mean (SD) & $14.88(4.8)$ & $13.8(3.19)$ & $14.28(4.68)$ & $14.12(4.87)$ & 0.74 \\
\hline \multicolumn{6}{|l|}{ Study arm, \% (n) } \\
\hline Control & $45.45(30)$ & $35.00(7)$ & $62.69(42)$ & $43.14(22)$ & \multirow[t]{2}{*}{0.07} \\
\hline Intervention & $54.55(36)$ & $65.00(13)$ & $37.31(25)$ & $56.86(29)$ & \\
\hline
\end{tabular}

ANOVA for continuous variables; Chi-square for nominal variables; ${ }^{a}$ Kruskall-Wallis for ordinal variables

\section{Results}

Tables 2 and 3 present descriptive and bivariate statistics of psychosocial covariates with the four violence categories (none, IPV 'Only', VAC 'Only', IPV and VAC), separated for male and female caregiver-adolescent dyads, respectively. The average age of adolescents range from 13.99 to 14.50 years for those in the male caregiver dyad and 13.85 to 13.99 years for those in the female caregiver dyads. The percentage of adolescents who reported living mostly with a biological mother ranged from 35.71 to $47.58 \%$ for those in the female caregiver dyads and 25.37 to $35.0 \%$ in the male caregiver dyads. Most adolescents did not report any physical disability (male caregiver-dyad range: 75.76 to $85.0 \%$; female caregiverdyad range: 69.57 to $85.56 \%$ ). Caregivers' average age was $40.9(\mathrm{SD}=10.8)$. Most caregivers lived with their partner/spouse (90.7\%) and were of Catholic or Christian religion (79.2\%). A minority of caregivers, 9.76 to 
Table 3 Bivariate analysis of covariates with female caregiver-adolescent dyads

\begin{tabular}{|c|c|c|c|c|c|}
\hline & None & IPV 'Only' & VAC 'Only' & IPV and VAC & $p$ \\
\hline & $n=71$ & $n=46$ & $n=90$ & $n=124$ & \\
\hline \multicolumn{6}{|l|}{ Caregiver Report } \\
\hline Age, mean (SD) & $36.1(9.7)$ & $38.87(10.37)$ & $37.98(8.05)$ & $37.23(6.48)$ & 0.30 \\
\hline \multicolumn{6}{|l|}{ Education, \% (n) } \\
\hline Primary & $64.52(40)$ & $90.24(37)$ & $76.19(64)$ & $88.79(103)$ & \multirow[t]{2}{*}{$<0.01$} \\
\hline High School or more & $35.48(22)$ & $9.76(4)$ & $23.81(20)$ & $11.21(13)$ & \\
\hline \multicolumn{6}{|l|}{ Religion, \% (n) } \\
\hline Catholic/Christian & $81.43(57)$ & $76.09(35)$ & $76.67(69)$ & $79.03(98)$ & \multirow[t]{2}{*}{0.87} \\
\hline Muslim & $18.57(13)$ & $23.91(11)$ & $23.33(21)$ & $20.97(26)$ & \\
\hline SES, mean (SD) & $-0.01(0.24)$ & $-0.03(0.3)$ & $-0.1(0.29)$ & $-0.02(0.27)$ & 0.09 \\
\hline Mental distress (SRQ), mean (SD) & $4.72(3.62)$ & $6.72(4.64)$ & $5.21(3.93)$ & $7.3(4.07)$ & 0.00 \\
\hline Alcohol, median (min-max) ${ }^{a}$ & $0(0-1)$ & $0(0-2)$ & $0(0-4)$ & $0(0-4)$ & 0.07 \\
\hline \multicolumn{6}{|l|}{ Partner Living Status, \% (n) } \\
\hline Do not live together & $14.08(10)$ & $4.35(2)$ & $13.33(12)$ & $13.71(17)$ & \multirow[t]{2}{*}{0.36} \\
\hline Live together & $85.92(61)$ & $95.65(44)$ & $86.67(78)$ & $86.29(107)$ & \\
\hline Intimate Partner Emotional Attachment, mean (SD) & $14.87(4.6)$ & $17.37(5.49)$ & $15(5.7)$ & $18.56(6.52)$ & 0.00 \\
\hline Attitudes toward VAC, mean (SD) & $15.01(3.1)$ & $14.19(2.62)$ & $14.08(2.74)$ & $13.74(2.89)$ & 0.04 \\
\hline \multicolumn{6}{|l|}{ Adolescent Report } \\
\hline \multicolumn{6}{|l|}{ Sex, \% (n) } \\
\hline Female & $45.07(32)$ & $50(23)$ & $36.67(33)$ & $37.9(47)$ & \multirow[t]{2}{*}{0.36} \\
\hline Male & $54.93(39)$ & $50(23)$ & $63.33(57)$ & $62.1(77)$ & \\
\hline Children age, mean (SD) & $13.99(1.18)$ & $13.85(1.17)$ & $13.99(1.24)$ & $13.89(1.24)$ & 0.87 \\
\hline \multicolumn{6}{|l|}{ Physical disability, \% (n) } \\
\hline No & $80.28(57)$ & $69.57(32)$ & $85.56(77)$ & $76.61(95)$ & \multirow[t]{2}{*}{0.15} \\
\hline Yes & $19.72(14)$ & $30.43(14)$ & $14.44(13)$ & $23.39(29)$ & \\
\hline \multicolumn{6}{|l|}{ Family Structure, \% (n) } \\
\hline Lives with bio mother & $35.71(25)$ & $41.3(19)$ & $40(36)$ & $47.58(59)$ & \multirow[t]{4}{*}{0.81} \\
\hline Lives with bio father & $7.14(5)$ & $6.52(3)$ & $6.67(6)$ & $3.23(4)$ & \\
\hline Lives with both bio parents & $25.71(18)$ & $19.57(9)$ & $24.44(22)$ & $25(31)$ & \\
\hline Lives with neither bio parent & $31.43(22)$ & $32.61(15)$ & $28.89(26)$ & $24.19(30)$ & \\
\hline Mental health difficulties (SDQ), mean (SD) & $14.3(5.29)$ & $15.39(6.36)$ & $15.32(5.51)$ & $14.35(5.08)$ & 0.42 \\
\hline Belong, mean (SD) & $7.23(2.1)$ & $7.48(2.22)$ & $7.21(2.31)$ & $7.27(2.16)$ & 0.92 \\
\hline \multicolumn{6}{|l|}{ Study arm, \% (n) } \\
\hline Control & $42.25(30)$ & $52.17(24)$ & $54.44(49)$ & $52.42(65)$ & \multirow[t]{2}{*}{0.46} \\
\hline Intervention & $57.75(41)$ & $47.83(22)$ & $45.56(41)$ & $47.58(59)$ & \\
\hline
\end{tabular}

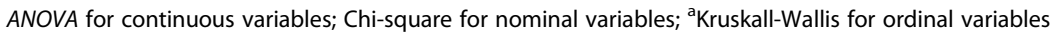

$35.48 \%$ of women and 19.61 to $33.33 \%$ of men, had attended secondary school or beyond. Caregivers reported being with their intimate partner for a median number of 17 years and most said that they drank 0 or only 1-2 days in the last month.

Bivariate analyses were conducted across four categories of adolescent-caregiver dyads (no violence, IPV 'only', VAC 'only', or IPV-VAC), separately for male and female caregiver-adolescent dyads. Significant differences were observed for the following variables for female caregiveradolescent dyads: education (female caregivers with higher education or above were more likely to be in the 'no violence' dyad), mental distress (lower among female caregivers reporting no violence), and perception of closeness to one's intimate partner (female caregiveradolescent dyads with no violence were characterized with higher levels of closeness), and attitudes towards VAC (female caregiver-adolescent dyads with no 
violence reported more progressive attitudes). Significant demographic and/or psychosocial differences between violence categories observed for male caregiveradolescent dyads included: age (older male caregivers were more likely to report no violence); mental distress (less among male caregivers in the dyads reporting no violence); and attitudes towards VAC (male caregiver reporting no violence also reported more progressive attitudes).

Table 4 presents the percentage overlap of VAC and IPV among the adolescent-caregiver dyads, separated by sex of the caregiver. Over one third (37.46\%) of female caregiver-adolescent dyads reported both VAC and IPV, compared to $25.0 \%$ of male caregiver-adolescent dyads. In contrast, $32.4 \%$ of men caregivers reported no violence, compared to $21.45 \%$ of women caregivers. The combined totals for both male and female caregiver dyads found 33\% of dyads reported both IPV and VAC, $29 \%$ reported VAC "only", $12 \%$ reported IPV "only", and $26 \%$ reported neither VAC or IPV. Overall, dyads reporting any IPV were more likely to report any VAC $\left(x^{2}=\right.$ $14.9, \mathrm{df}=1, p<.001)$. This association remained significant on separate analyses of reports from women and male caregiver.

In order to explore associations between risk factors and reporting of IPV, VAC, or both, we ran separate multinomial logistic regression models for female and male caregivers. Below we summarize the associations that were significant (or approaching significance), comparing dyads reporting either IPV and VAC, IPV 'Only', or VAC 'Only' to those with no reported violence (Table 5). The results for dyads with female caregivers showed that those with IPVVAC were characterized as caregivers with less education, lower SES, more mental distress, more frequent alcohol use, slightly longer relationship duration (approaching significance), and less emotional attachment to their intimate partner. Dyads of male caregivers with IPV-VAC were characterized as having more frequent caregiver alcohol use (approaching significance),

less emotional attachment to their intimate partner, and attitudes more accepting of using violence against children as discipline.

Dyads with female caregivers with VAC 'only' were more likely to have lower SES and more frequent caregiver alcohol use (approaching significance). The male caregiver dyads with VAC 'only' were characterized as having younger caregivers and adolescent boys (rather than girls).

Dyads of female caregivers with 'only' IPV were associated with lower education status and less reported emotional attachment to their intimate partner. Male caregivers with 'only' IPV reported having a Muslim religious affiliation (approaching significance), more alcohol use (approaching significance), shorter relationship duration (approaching significance), less emotional attachment to their partner, and adolescents reporting increased connectedness in the family (approaching significance).

\section{Discussion}

This exploratory study is one of the first in any lowor middle-income country (LMIC) to investigate the overlap and contributing factors of intimate partner violence against women (IPV) and violence against children (VAC) using a sample of adolescents and their caregivers in Uganda. Similar to previous research on the intersection of IPV and VAC from high income countries $[11,14,16]$, caregivers who reported perpetrating (men) or experiencing (women) IPV were also more likely to report perpetrating VAC. Over one third (37.46\%) of women reported experiencing IPV and using violence against children and $21.30 \%$ of men reported perpetrating both IPV and VAC. The 33\% rate of overlap between IPV and VAC is markedly higher than other studies primarily from the United States, where probability samples have found rates of $6-12 \%$ [65]. Overlap in the current study only captures violence experienced or perpetrated by the specific caregiver and adolescent interviewed; household rates that include violence from other caregivers or family members are likely to be higher. This evidence supports calls for violence researchers to begin "recognizing that co-occurrence is the norm, not the exception" [7], which may be particularly true in settings with overall higher rates of multiple forms of violence.

Results highlight the unique patterns of IPV and VAC in the family depending on caregiver sex. Consistent with IPV literature [66], female caregiver education and socioeconomic status were found to be protective factors for women from both experiencing IPV and using VAC. Secondary education may be associated with attitudes rejecting IPV (for which a measure was not included),

Table 4 Percentage of dyads reporting none, IPV 'Only', VAC 'Only', or IPV and VAC, by sex of caregiver

\begin{tabular}{lllll}
\hline & None & IPV 'Only' & VAC 'Only' & IPV and VAC \\
\hline Women & $21.45 \%(n=71)$ & $13.9 \%(n=46)$ & $27.19 \%(n=90)$ & $37.46 \%(n=124)$ \\
Men & $32.4 \%(n=66)$ & $9.8 \%(n=20)$ & $32.8 \%(n=67)$ & $25.0 \%(n=51)$ \\
\hline
\end{tabular}

Chi-square $=14.9, p=0.0007$; adjusted for clustering: schools 
Table 5 Multinomial logistic regressions of IPV and VAC, VAC only, and IPV only, compared to no violence dyads

\begin{tabular}{|c|c|c|c|c|c|c|}
\hline \multirow[b]{2}{*}{ Odd-ratio $(\mathrm{Cl})$} & \multicolumn{3}{|l|}{ Female Caregivers } & \multicolumn{3}{|l|}{ Male Caregivers } \\
\hline & $\begin{array}{l}\mathrm{IPV} \text { and } \mathrm{VAC} \\
(n=124)\end{array}$ & $\begin{array}{l}\text { VAC 'only' } \\
(n=90)\end{array}$ & $\begin{array}{l}\text { IPV 'only' } \\
(n=46)\end{array}$ & $\begin{array}{l}\text { IPV and VAC } \\
(n=51)\end{array}$ & $\begin{array}{l}\text { VAC 'only' } \\
(n=67)\end{array}$ & $\begin{array}{l}\text { IPV 'only' } \\
(n=20)\end{array}$ \\
\hline \multicolumn{7}{|l|}{ Caregiver Reports } \\
\hline Age (years) & $0.96(0.9-1.01)$ & $1.02(0.97-1.08)$ & $0.99(0.92-1.05)$ & $0.96(0.91-1.02)$ & $0.95(0.91-1)^{*}$ & $1(0.95-1.05)$ \\
\hline $\begin{array}{l}\text { Education (some secondary } \\
\text { or higher vs. primary or no) }\end{array}$ & $0.23(0.09-0.59)^{* *}$ & $0.52(0.21-1.26)$ & $0.3(0.09-0.98)^{*}$ & $0.87(0.29-2.61)$ & $0.97(0.37-2.51)$ & $0.9(0.25-3.29)$ \\
\hline Religious status ${ }^{a}$ & $1.42(0.61-3.32)$ & $1.21(0.52-2.86)$ & $1.43(0.53-3.86)$ & $1.62(0.51-5.1)$ & $1.7(0.6-4.85)$ & $3.22(0.86-12.18)^{*}$ \\
\hline SES & $0.26(0.07-1.01)^{*}$ & $0.13(0.03-0.51)^{* *}$ & $0.31(0.06-1.55)$ & $1.52(0.23-10.07)$ & $3.39(0.61-18.73)$ & $4.44(0.46-42.52)$ \\
\hline Mental Distress (SRQ) & $1.12(1.01-1.22)^{*}$ & $1.02(0.92-1.13)$ & $1.07(0.97-1.2)$ & $1.09(0.97-1.23)$ & $1.07(0.96-1.2)$ & $1.04(0.9-1.2)$ \\
\hline Alcohol Use & $3.03(0.99-9.3)^{*}$ & $2.59(0.84-8)^{¥}$ & $1.82(0.48-6.96)$ & $1.26(0.95-1.67)^{¥}$ & $1.09(0.83-1.43)$ & $1.38(0.99-1.93)^{¥}$ \\
\hline $\begin{array}{l}\text { Intimate Partner Current Living } \\
\text { Status (living together vs. not) }\end{array}$ & $1.09(0.37-3.22)$ & $0.92(0.31-2.77)$ & $2.39(0.5-11.36)$ & $6.42(0.46-90.02)$ & $4.1(0.55-30.27)$ & $3.97(0.39-40.04)$ \\
\hline $\begin{array}{l}\text { Intimate Partner Relationship } \\
\text { Length (years) }\end{array}$ & $1.05(0.99-1.11)^{*}$ & $1.01(0.95-1.06)$ & $1.04(0.98-1.12)$ & $1.03(0.97-1.09)$ & $1.01(0.95-1.06)$ & $0.94(0.87-1.01)^{*}$ \\
\hline $\begin{array}{l}\text { Intimate Partner Emotional } \\
\text { Attachment }\end{array}$ & $0.9(0.85-0.97)^{* *}$ & $0.99(0.93-1.06)$ & $0.92(0.86-1)^{* *}$ & $0.8(0.71-0.91)^{* * *}$ & $0.96(0.86-1.08)$ & $0.84(0.73-0.98)^{*}$ \\
\hline Attitudes against VAC & $0.95(0.84-1.07)$ & $0.92(0.82-1.05)$ & $0.94(0.81-1.09)$ & $0.86(0.73-1)^{*}$ & $0.94(0.82-1.07)$ & $0.96(0.79-1.15)$ \\
\hline \multicolumn{7}{|l|}{ Adolescent Reports } \\
\hline Age (years) & $0.95(0.73-1.25)$ & $1.02(0.77-1.35)$ & $0.92(0.67-1.28)$ & $1.27(0.86-1.88)$ & $0.86(0.61-1.22)$ & $1.39(0.9-2.18)$ \\
\hline Sex of child (girls vs. boys) & $1.14(0.58-2.23)$ & $1.32(0.66-2.61)$ & $0.76(0.34-1.65)$ & $1.11(0.45-2.72)$ & $0.39(0.17-0.87)^{*}$ & $0.93(0.31-2.77)$ \\
\hline Mental Distress (SDQ) & $0.98(0.92-1.04)$ & $1.04(0.98-1.11)$ & $1.02(0.95-1.09)$ & $0.95(0.87-1.05)$ & $0.98(0.9-1.07)$ & $0.95(0.84-1.06)$ \\
\hline Physical Disability & $0.97(0.44-2.18)$ & $0.63(0.26-1.51)$ & $1.35(0.54-3.39)$ & $0.63(0.25-1.52)$ & $0.55(0.24-1.26)$ & $0.76(0.26-2.2)$ \\
\hline $\begin{array}{l}\text { Lives with at least one } \\
\text { biological parent }\end{array}$ & $1.68(0.79-3.53)$ & $1.52(0.7-3.32)$ & $1.84(0.76-4.48)$ & $0.93(0.34-2.51)$ & $1.23(0.49-3.13)$ & $1.75(0.49-6.23)$ \\
\hline $\begin{array}{l}\text { Lives with both biological } \\
\text { parents }\end{array}$ & $0.99(0.39-2.51)$ & $1.48(0.59-3.67)$ & $1.06(0.35-3.25)$ & $0.9(0.25-3.22)$ & $2.34(0.8-6.75)$ & $3.35(0.75-14.88)$ \\
\hline $\begin{array}{l}\text { Child sense of belonging } \\
\text { and safety at home }\end{array}$ & $1(0.86-1.16)$ & $0.98(0.84-1.14)$ & $1.06(0.89-1.27)$ & $0.98(0.79-1.22)$ & $1.01(0.81-1.26)$ & $1.28(0.99-1.67)^{¥}$ \\
\hline Intervention & $0.63(0.32-1.23)$ & $0.76(0.38-1.51)$ & $0.61(0.27-1.38)$ & $1.4(0.57-3.42)$ & $0.61(0.27-1.34)$ & $1.75(0.58-5.21)$ \\
\hline
\end{tabular}

${ }^{\mathrm{a}}$ Muslim affiliation compared to Christian/Catholic (ref); ${ }^{\mathrm{b}}$ Compared to no biological parents; ${ }^{*} p<0.10 ;{ }^{*} p<0.05 ;{ }^{* *} p<0.01 ;{ }^{* * *} p<0.001$

and for women, increased employment and time outside the home. Limited resources or upward mobility, as evident from the SES results, may uniquely affect women's likelihood to experience violence from her partner and/ or navigate stress through the use of violence against children-consistent with other research indicating that economic marginalization and/or dependence on men compromises a women's ability to exit violent relationships [67].

Sex of the child was the only statistically significant adolescent factors predicting risk of violence (family connectedness was approaching significance in the male caregiver IPV 'only' dyad). Results indicate that compared to girls, boys are at a higher risk of experiencing violence by male caregivers in the VAC 'only' dyad. This finding may reflect that there is greater social acceptance of men's use of violence against boys compared to girls.

Female caregivers who both experience IPV and use VAC (the IPV and VAC dyads) reported more mental distress, compared to those neither experiencing or perpetrating violence (no violence dyads). Women's mental distress was not associated with experiencing IPV 'only' or perpetrating VAC 'only', suggesting there is added distress for women associated with being in a family with both IPV and VAC. A recent qualitative study in Uganda exploring patterns of intersecting IPV and VAC revealed how-in the context of patriarchal families and male authority-women who are experiencing IPV may at times use violence against their children as a way to redirect or transfer their own trauma and powerlessness vis-à-vis their husbands [37]. Given the link between poor mental health and violence in the IPV literature [3, 44], further research is needed to understand if this finding holds in other contexts. Neither adolescents' nor men's reports of mental health was associated with an increased risk of violence in any of the dyads.

While alcohol use is a risk factor for men's use of IPV [68] and caregiver use of VAC [69], this study is one of 
the first to examine the association of alcohol and cooccurring IPV and VAC. Female caregiver reports of more frequent alcohol use were significantly associated with their likelihood of being in the IPV and VAC dyads, and was approaching significance in the IPV 'only' dyad. When considered alongside the finding related to women's increased mental distress (reported above), women's alcohol use may be a coping strategy for their broader experiences of violence and powerlessness in the family [37], which at the same time exacerbates their own use of violence against children. Approaching significance, male caregivers in the IPV 'only' dyad and the IPV and VAC dyads also reported more frequent alcohol use. Qualitative research has found men's alcohol use to be a compounding factor for violence in the family, as well as a proximate trigger for men's use of both IPV and VAC [37]. Overall associations between violence and alcohol is among the most consistent result in the analysis, underscoring that more research is needed to tease out the dynamics between caregivers' alcohol use in families with co-occurring IPV and VAC, including female caregivers' alcohol use.

Stronger perceived emotional attachment between intimate partners consistently emerged as a protective factor for the IPV-VAC dyads and IPV 'only' dyads for both male and female caregivers. This emphasis on the quality of intimate relationships has also been raised in previous research from Uganda, for example in explaining processes of change towards healthier relationship dynamics between couples previously experiencing violence [70]. Of particular interest is the inverse association between higher intimate partner emotional attachment and dyads with both IPV and VAC. Perhaps women and men with stronger emotional attachment are less likely to experience/perpetrate IPV, which also reduces their conflict over parenting and their use of VAC. Alternatively, partners who practice more positive parenting and less violence may have less conflict in their intimate relationships and subsequently feel more positive attachment to their partner. Regardless, these findings emphasize that family relationships are interdependent, whereby the perceived quality of the relationship between adults also affects children in the home.

Men with attitudes rejecting VAC were less likely to report using both IPV and VAC. This aligns with expectations that lower acceptance of violence correlates with less violent behaviors [71]. While the survey did not include attitudinal questions about IPV, future research should investigate whether or not attitudes rejecting IPV may also result in reduced VAC perpetration.

This study had some limitations. Caregivers were recruited through the adolescents, resulting in a lower caregiver response rate. The sample of adolescents whose caregivers participated in the study (although similar in age, sex, and SES) reported better attendance in the past week, perhaps biasing the dyad sample (See Appendix C). Caregiver reports of perpetrating VAC against the specific adolescent in the sample were used, because adolescents were asked about perpetration from any caregiver. Perpetration of VAC may have been under-reported by caregivers, although violence for purposes of disciplining children is widely accepted in Uganda and unlikely to be significantly under-reported [32]. Using caregiver reports may have had other impact on results, such as a non-significant association with child mental health. Both primary and non-primary caregivers completed the survey, perhaps altering the results and underestimating the children's exposure to violence if only primary caregivers had been interviewed. Data came from a school-based sample and results may differ from dyads with an adolescent not in school. In addition, the primary Good School Study was not explicitly designed for these analyses, and subsequently some of the sub-groups have a small sample size (notably male caregiver-adolescent dyads in the 'IPV-only' group), potentially limiting statistical power. Finally, given the cross-sectional nature of the data, we cannot draw conclusions about hypothesized causal relationships between variables. For example, causal ordering is particularly ambiguous for the relationship between intimate partner violence and intimate partner living status or emotional attachment with an intimate partner.

\section{Conclusions}

Results from this study suggest several implications for violence prevention and response programming and research. While VAC and IPV are affecting the majority of families/dyads, one third of dyads are reporting both types of violence concurrently. Efforts to integrate prevention programming may consider addressing the associated factors, especially in families characterized by both IPV and VAC (i.e., women's education, socioeconomic status, alcohol use, and emotional attachment between intimate partners). Furthermore, almost all factors associated with either the VAC 'only' or IPV 'only' dyads, were also associated with the IPV and VAC dyads. More evaluative research is needed to better understand the potential 'spillover effects' of violence prevention interventions targeting either VAC or IPV on the prevention of other types of violence. For example, VAC prevention programming (especially ones that focus on poorer communities, or programs which may focus on preventing violence against girls) should also measure their potential effects on preventing IPV. Likewise, IPV prevention programming that focuses on improving women's education or intimate partner relationships should also evaluate potential outcomes on VAC. 


\section{Appendix A}

Table 6 Socioeconomic Status Items and Results of Confirmatory Factor Analysis

\begin{tabular}{|c|c|c|c|}
\hline Item & Scale & Loading & \\
\hline & & Initial results & After excluding non-sig. Items \\
\hline $\begin{array}{l}\text { Do you own or rent a property, live somewhere without paying, } \\
\text { or does your employer pay for your accommodation? }\end{array}$ & $\begin{array}{l}1=\text { Does not own } \\
2=\text { Owns }\end{array}$ & .31 & .36 \\
\hline $\begin{array}{l}\text { How many children aged } 17 \text { years and younger } \\
\text { sleep in the same sleeping area with you? }\end{array}$ & $\begin{array}{l}0=\text { No children } \\
1=\text { One child } \\
2=\text { More than one child }\end{array}$ & .27 & .25 \\
\hline $\begin{array}{l}\text { Thinking about your house where you live now, } \\
\text { what is the main material of the floor }\end{array}$ & $\begin{array}{l}1=\text { Earth, sand, or dung } \\
2=\text { Ceramic, cement, carpet }\end{array}$ & .68 & .70 \\
\hline Does your household own electricity? & $1=$ No $2=$ Yes & .92 & .93 \\
\hline Does your household own a radio? & $1=$ No $2=$ Yes & .34 & .31 \\
\hline Does your household own a television? & $1=$ No $2=$ Yes & .97 & .97 \\
\hline Does any member of your household own a watch? & $1=$ No $2=$ Yes & .38 & .37 \\
\hline Does any member of your household own a mobile phone? & $1=$ No $2=$ Yes & .49 & .44 \\
\hline Does any member of your household own a motorcycle? & $1=$ No $2=$ Yes & .29 & .26 \\
\hline $\begin{array}{l}\text { Does any member of your household own land that } \\
\text { can be used for agriculture? }\end{array}$ & $1=$ No $2=$ Yes & .16 & - \\
\hline $\begin{array}{l}\text { Does any member of your household own livestock, } \\
\text { herds, other farm animals, or poultry? }\end{array}$ & $1=$ No $2=$ Yes & .11 & - \\
\hline Does any member of your household own a bicycle? ${ }^{\sharp}$ & $1=$ No $2=$ Yes & .06 & \\
\hline $\begin{array}{l}\text { Yesterday, how many meals did you eat? } \\
\text { (Ate at least two meals yesterday) }\end{array}$ & $\begin{array}{l}0=\text { No or one meal } \\
1=\text { Two or more meals }\end{array}$ & .10 & - \\
\hline $\begin{array}{l}\text { How many adults aged } 18 \text { years and older sleep in the same } \\
\text { sleeping area with you? }\end{array}$ & $\begin{array}{l}0=\text { No adults } \\
1=\text { One adult } \\
2=\text { More than one adult }\end{array}$ & .07 & - \\
\hline
\end{tabular}

${ }^{*}$ dropped because of non-significant $p$ value $(>.05)$

\section{Appendix B}

Table 7 Missing Data

\begin{tabular}{lllll}
\hline & & Women & & Men \\
& $\mathrm{n}$ & $\%$ & $\mathrm{n}$ & $\%$ \\
\hline VAC-IPV & 331 & 0.00 & 204 & 0.00 \\
Education & 303 & 8.46 & 198 & 2.94 \\
Relationship Status & 331 & 0.00 & 204 & 0.00 \\
Religion & 330 & 0.30 & 204 & 0.00 \\
Family structure & 330 & 0.30 & 204 & 0.00 \\
Child Disability & 331 & 0.00 & 204 & 0.00 \\
VAC attitudes & 308 & 6.95 & 193 & 5.39 \\
CHILD Belong & 331 & 0.00 & 203 & 0.49 \\
Intimate Partner Emotional Attachment & 331 & 0.00 & 204 & 0.00 \\
Child mental health (SDQ) & 331 & 0.00 & 204 & 0.00 \\
Caregiver mental health (SRQ) & 331 & 0.00 & 204 & 0.00 \\
Adolescent age & 330 & 0.30 & 204 & 0.00 \\
Caregiver age & 331 & 0.00 & 204 & 0.00 \\
Child sex & 331 & 0.00 & 204 & 0.00 \\
Alcohol & 331 & 0.00 & 202 & 0.98 \\
SES & 331 & 0.00 & 204 & 0.00 \\
\hline
\end{tabular}

\section{Appendix C}

Table 8 Demographic characteristics of full adolescent sample from class P7, compared to adolescent sample from class P7 whose caregivers participated in survey (Note: all P7 students' caregivers were invited to participate)

\begin{tabular}{lll}
\hline & $\begin{array}{l}\text { Full adolescent P7 } \\
\text { sample }(n=1171)\end{array}$ & $\begin{array}{l}\text { Adolescent P7 sample with } \\
\text { matched caregivers }(n=800)\end{array}$ \\
\hline $\begin{array}{l}\text { Age, mean (SD) } \\
\text { Sex, \% (n) }\end{array}$ & $13.95(1.3)$ & $13.99(1.2)$ \\
Female & $54.57(639)$ & $56.00(448)$ \\
$\quad$ Male & $45.43(532)$ & $44.00(352)$
\end{tabular}

Past week school absences, \% (n)

$\begin{array}{lll}\text { No days missed } & 85.89(998) & 82.84(657) \\ \begin{array}{l}\text { One or more days } \\ \text { missed }\end{array} & 14.11(164) & 17.16(140) \\ \begin{array}{l}\text { Meals eaten yesterday } \\ 1 \text { meal or fewer }\end{array} & 13.25(155) & 15.18(121) \\ 2 \text { meals } & 38.89(455) & 40.78(325) \\ 3 \text { or more meals } & 47.86(560) & 44.04(351)\end{array}$




\section{Abbreviations}

ANOVA: Analysis of variance; CFA: Confirmatory factor analysis; CFI: Comparative fit index; DF: Degrees of freedom; GST: Good School Toolkit; IPSCAN: International Society for the Prevention of Child Abuse and Neglect Screening Tool; IPV: Intimate partner violence against women; LMIC: Low- or middle-income country; MLR: Maximum Likelihood with Robust standard error; P: P-value; RMSEA: Root mean square error of approximation; SD: Standard deviation; SDQ: Strengths and difficulties questionnaire; SES: Socioeconomic status; SPSS: Statistical Package for Social Sciences; SRQ: Self-report questionnaire; TLI: Tucker-Lewis index; VAC: Violence against children; WHO: World Health Organization; WLSMV: Weighted Least Square with adjusted Mean and Variance

\section{Acknowledgements}

Not applicable.

\section{Author's contributions}

CC led the design of the study, advised on data analysis and interpretation, obtained funding, and drafted the manuscript. SN participated in the design of the study, advised on data analysis and interpretation, obtained funding, and drafted the manuscript. ANP led the process of data analysis, participated in data interpretation, and drafted the manuscript. MW and LM participated in the interpretation of the data and writing the manuscript. JN participated in data collection and writing of the manuscript. LK and EA advised on data analysis, participated in data interpretation and writing of the manuscript. Cl participated in data interpretation and writing of the manuscript. DN initiated the idea to do the parent study (the Good Schools Study), participated in the design of the parent study, obtained funding, participated in data interpretation and participated in drafting of the manuscript. KD designed the parent study, participated in data collection, data interpretation and obtained funding. All authors read and approved the final manuscript.

\section{Funding}

This work was funded by the Sexual Violence Research Initiative (to $C$ Carlson and S. Namy), MRC/DfID/Wellcome Trust via the Joint Global Health Trials Scheme (to K. Devries), and the Hewlett Foundation and the Oak Foundation (to D. Naker). Funders were not involved in the design of the study, data collection, analysis, interpretation, or writing the manuscript.

\section{Availability of data and materials}

The data are being collected as part of a project with multiple partners, and the authors have a donor agreement that all data will remain within the project until being made available via a controlled access procedure in 2024 The datasets generated and/or analyzed during the current study will be publicly available on The London School of Hygiene \& Tropical Medicine repository at that time.

\section{Ethics approval and consent to participate}

The study was approved by the London School of Hygiene and Tropical Medicine Ethics Committee (6183) and the Uganda National Council for Science and Technology (SS2520). All procedures performed in studies involving human participants were in accordance with the ethical standards of the institutional and/or national research committee and with the 1964 Helsinki declaration and its later amendments or comparable ethical standards. Written voluntary informed consent was obtained from all individual participants included in the study. Headteachers provided consent for schools to participate in the study. Caregivers were notified and could opt children out of participation in survey data collection. Children themselves provided consent for participation. Caregivers provided consent for participation in survey data collection.

\section{Consent for publication}

Not applicable.

\section{Competing interests}

The authors declare that they have no competing interests.

\section{Author details}

'University of Alabama, School of Social Work, 3026 Little Hall, Box 870314 Tuscaloosa, AL 35487-0314, USA. ${ }^{2}$ Raising Voices, Kampala, Uganda.
${ }^{3}$ Columbia University, Social Intervention Group, New York, USA. ${ }^{4}$ Columbia University, Department of Psychiatry, New York, USA. ${ }^{5}$ London School of Hygiene and Tropical Medicine, London, UK.

Received: 7 July 2018 Accepted: 20 December 2019

Published online: 29 January 2020

\section{References}

1. Devries KM, Mak JY, Garcia-Moreno C, Petzold M, Child JC, Falder G, et al. Global health. The global prevalence of intimate partner violence against women. Science. 2013;340(6140):1527-8.

2. Hillis S, Mercy J, Amobi A, Kress H. Global prevalence of past-year violence against children: a systematic review and minimum estimates. Pediatrics. 2016;137(3):e20154079

3. Ellsberg $M$, Jansen HAFM, Heise L, Watts $\mathrm{CH}$, Garcia-Moreno C. Intimate partner violence and women's physical and mental health in the WHO multi-country study on women's health and domestic violence: an observational study. Lancet. 2008;371(9619):1165-72.

4. Norman RE, Byambaa M, De R, Butchart A, Scott J, Vos T. The long-term health consequences of child physical abuse, emotional abuse, and neglect: a systematic review and meta-analysis. PLoS Med. 2012;9(11):e1001349.

5. Guedes A, Bott S, Garcia-Moreno C, Colombini M. Bridging the gaps: a global review of intersections of violence against women and violence against children, vol. 2016; 2016. p. 9.

6. Fry DA, Elliott SP. Understanding the linkages between violence against women and violence against children. Lancet Glob Health. 2017;5(5): e472-e3.

7. Hamby S, Grych J. The web of violence: exploring connections among different forms of interpersonal violence and abuse. London: Springer; 2013.

8. Maternowska C, Shakel R, Carlson C, Levtov R, Heise L. The global politics of the age-gender divide: Violence against women and violence against children. under review.

9. Moore JG. Yo-yo children - victims of matrimonial violence. Child welfare. 1975;54(8):557-66.

10. Levine MB. Interparental violence and its effect on the children: a study of 50 families in general practice. Med Sci Law. 1975;15(3):172.

11. Appel AE, Holden GW. The co-occurrence of spouse and physical child abuse: a review and appraisal. J Fam Psychol. 1998;12(4):578.

12. Edleson JL. The overlap between Child maltreatment and woman battering. Violence Against Women. 1999;5(2):134-54.

13. Edleson JL. Do batterers' programs work. University of Minnesota and Domestic Abuse Project Inc, paper presented at the International Study Group on the Future of Intervention with Battered Women and Their Families, Israel; 1995.

14. Hamby S, Finkelhor D, Turner $H$, Ormrod R. The overlap of witnessing partner violence with child maltreatment and other victimizations in a nationally representative survey of youth. Child Abuse Negl. 2010;34(10): 734-41.

15. Casanueva C, Martin SL, Runyan DK. Repeated reports for child maltreatment among intimate partner violence victims: findings from the National Survey of Child and adolescent well-being. Child Abuse Negl. 2009; 33(2):84-93.

16. Hartley CC. The co-occurrence of Child maltreatment and domestic violence: examining both neglect and Child physical abuse. Child Maltreatment. 2002;7(4):349-58.

17. Bourassa C. Co-occurrence of Interparental violence and Child physical abuse and It's effect on the adolescents' behavior. J Fam Violence. 2007; 22(8):691-701.

18. Mbilinyi LF, Edleson JL, Hagemeister AK, Beeman SK. What happens to children when their mothers are battered? Results from a four City anonymous telephone survey. J Fam Violence. 2007;22(5):309-17.

19. Tajima EA. Correlates of the co-occurrence of wife abuse and child abuse among a representative sample. J Fam Violence. 2004;19(6):391-402.

20. Damant D, Lapierre S, Lebossé C, Thibault S, Gv L, Hamelin-Brabant L, et al. Women's abuse of their children in the context on domestic violence: reflection from women's accounts. Child Fam Soc Work. 2010;15(1):12-21.

21. Beeman SK, Hagemeister AK, Edleson JL. Case assessment and service receipt in families experiencing both Child maltreatment and woman battering. J Int Violence. 2001;16(5):437-58.

22. O'Keefe M. Linking marital violence, mother-child/father-child aggression, and child behavior problems. J Fam Violence. 1994;9(1):63-78. 
23. Ross SM. Risk of physical abuse to children of spouse abusing parents. Child Abuse Negl. 1996;20(7):589-98.

24. Gracia E, López-Quílez A, Marco M, Lila M. Neighborhood characteristics and violence behind closed doors: the spatial overlap of child maltreatment and intimate partner violence. PLoS One. 2018;13(6):e0198684.

25. Wherry JN, Medford EA, Corson K. Symptomatology of Children Exposed to Domestic Violence. J Child Adolescent Trauma. 2015;8(4):277-85.

26. Moylan CA, Herrenkohl TI, Sousa C, Tajima EA, Herrenkohl RC, Russo MJ. The effects of Child abuse and exposure to domestic violence on adolescent internalizing and externalizing behavior problems. J Fam Violence. 2010; 25(1):53-63.

27. Maniglio R. The impact of child sexual abuse on health: a systematic review of reviews. Clin Psychol Rev. 2009;29(7):647-57.

28. Fergusson DM, Boden JM, Horwood LJ. Exposure to childhood sexual and physical abuse and adjustment in early adulthood. Child Abuse Negl. 2008; 32(6):607-19.

29. MacMillan $\mathrm{HL}$, Fleming JE, Streiner DL, Lin E, Boyle MH, Jamieson E, et al. Childhood abuse and lifetime psychopathology in a community sample. Am J Psychiatr. 2001;158(11):1878-83.

30. Grethel SM. Correlates of psychological symptoms among children exposed to domestic violence: severity of domestic violence exposure, child abuse, and psychosocial stressors: Pepperdine University; 2004.

31. Fieggen A, Wiemann M, Brown C, Van As A, Swingler G, Peter J. Inhuman shields-children caught in the crossfire of domestic violence: original article. S Afr Med J. 2004;94(4):293-6.

32. Ayinmode B, Tunde-Ayinmode M. Family violence among mothers seen at the University of Ilorin Teaching Hospital, Ilorin. Niger S Afr J Psychiatry. 2009;14(3):76-83.

33. Saile R, Ertl V, Neuner F, Catani C. Does war contribute to family violence against children? Findings from a two-generational multi-informant study in northern Uganda. Child Abuse Negl. 2014;38(1):135-46.

34. HEISE LL. Violence against women:an integrated. Ecol Framework Violence Against Women. 1998;4(3):262-90.

35. Belsky J. Child maltreatment: an ecological integration. Am Psychol. 1980; 35(4):320-35.

36. Gracia E, Rodriguez CM, Martín-Fernández M, Lila M. Acceptability of family violence: underlying ties between intimate partner violence and Child abuse. J Int Violence. 2017; https://doi.org/10.1177/0886260517707310.

37. Namy S, Carlson C, O'Hara K, Nakuti J, Bukuluki P, Lwanyaaga J, et al. Towards a feminist understanding of intersecting violence against women and children in the family. Soc Sci Med. 2017;184:40-8.

38. Dekel B, Abrahams N, Andipatin M. Exploring the Intersection Between Violence Against Women and Children from the Perspective of Parents Convicted of Child Homicide. J Fam Violence. 2018;34(1):9-20.

39. Heise L. What works to prevent partner violence? An evidence overview. London: STRIVE, London School of Hygiene and Tropical Medicine; 2011

40. WHO/ISPCAN. Preventing child maltreatment: A guide to taking action and generating evidence. Geneva: World Health Organization/International. World Health Organization/International Society for Prevention of Child Abuse and Neglect; 2006.

41. Heise LL, Kotsadam A. Cross-national and multilevel correlates of partner violence: an analysis of data from population-based surveys. Lancet Glob Health. 2015:3(6):e332-e40.

42. Machisa MT, Christofides N, Jewkes R. Structural pathways between Child abuse, poor mental health outcomes and male-perpetrated intimate partner violence (IPV). PLoS One. 2016;11(3):e0150986.

43. Oram S, Trevillion K, Khalifeh H, Feder G, Howard L. Systematic review and meta-analysis of psychiatric disorder and the perpetration of partner violence2013. 1-16 p.

44. Devries KM, Mak JY, Bacchus LJ, Child JC, Falder G, Petzold M, et al. Intimate partner violence and incident depressive symptoms and suicide attempts: a systematic review of longitudinal studies. PLoS Med. 2013;10(5):e1001439

45. Reading R, Bissell S, Goldhagen J, Harwin J, Masson J, Moynihan S, et al. Promotion of children's rights and prevention of child maltreatment. Lancet. 2009:373(9660):332-43

46. Stith SM, Liu T, Davies LC, Boykin EL, Alder MC, Harris JM, et al. Risk factors in child maltreatment: a meta-analytic review of the literature. Aggress Violent Behav. 2009;14(1):13-29.

47. Devries KM, Allen E, Child JC, Walakira E, Parkes J, Elbourne D, et al. The good schools toolkit to prevent violence against children in Ugandan primary schools: study protocol for a cluster randomised controlled trial. Trials. 2013;14(1):232

48. Devries KM, Knight L, Child JC, Mirembe A, Nakuti J, Jones R, et al. The Good School Toolkit for reducing physical violence from school staff to primary school students: a cluster-randomised controlled trial in Uganda. Lancet Glob Health. 3(7):e378-e86.

49. Devries KM, Child JC, Elbourne D, Naker D, Heise L. "I never expected that it would happen, coming to ask me such questions":ethical aspects of asking children about violence in resource poor settings. Trials. 2015; 16:516.

50. Ellsberg M, Heise L. Researching violence against women: a practical guide for researchers and activists. World Health Organization, PATH: Washingon; 2005

51. Merg C. Ethical principles, dilemmas and risks in collecting data on violence against children: a review of available literature. New York: Statistics and Monitoring Section/Division of Policy and Strategy, UNICEF; 2012.

52. Devries KM, Child JC, Allen E, Walakira E, Parkes J, Naker D. School violence, mental health, and educational performance in Uganda. Pediatrics. 2014; 133(1):e129-37.

53. Muthén LK, Muthén BO. Mplus User's Gude. 17th ed. Los Angeles: Muthén \& Muthén; 1998. 2012

54. Bentler PM. Comparative fit indexes in structural models. Psychol Bull. 1990; 107(2):238-46.

55. Hu L-T, Bentler P. Evaluating model fit. In: Hoyle RH, editor. Structural equation modeling concepts, issues, and applications. London: Sage; 1995. p. 76-99.

56. $\mathrm{Hu}$ L, Bentler PM. Cutoff criteria for fit indexes in covariance structure analysis: conventional criteria versus new alternatives. Struct Equ Model Multidiscip J. 1999;6(1):1-55.

57. Zumbo BD, Gadermann AM, Zeisser C. Ordinal versions of coefficients alpha and Theta for Likert rating scales. J Mod Appl Stat Methods. 2007;6(1):20-9.

58. Beusenberg M, Orley J. A User's guide to the self reporting questionnaire (SRQ). Geneva: World Health Organization; 1994.

59. Goodman R. Psychometric properties of the strengths and difficulties questionnaire. J Am Acad Child Adolesc Psychiatry. 2001;40(11):1337-45.

60. McQueen MB, Boardman JD, Domingue BW, Smolen A, Tabor J, KilleyaJones $L$, et al. The National Longitudinal Study of adolescent to adult health (add health) sibling pairs genome-wide data. Behav Genet. 2015; 45(1):12-23.

61. Fraley CR, Heffernan ME, Vicary AM, Brumbaugh CC. The experiences in close relationships-relationship structures questionnaire: a method for assessing attachment orientations across relationships. Psychol Assess. 2011; 23(3):615-25.

62. Zolotor AJ, Runyan DK, Dunne MP, Jain D, Peturs HR, Ramirez C, et al. ISPCAN Child abuse screening tool Children's version (ICAST-C): instrument development and multi-national pilot testing. Child Abuse Negl. 2009; 33(11):833-41.

63. Thiese MS, Ronna B, Ott U. P value interpretations and considerations. J thorac Dis. 2016:8(9):E928-e31.

64. Namy S, Carlson C, Norcini Pala A, Faris D, Knight L, Allen E, et al. Gender, violence and resilience among Ugandan adolescents. Child Abuse Negl. 2017;70:303-14.

65. Margolin G, Gordis EB. Co-occurrence between marital aggression and parents' child abuse potential: the impact of cumulative stress. Violence Vict. 2003;18(3):243-58

66. Vyas S, Watts C. How does economic empowerment affect women's risk of intimate partner violence in low and middle income countries? A systematic review of published evidence. J Int Dev. 2009;21(5):577602.

67. Abramsky T, Watts CH, Garcia-Moreno C, Devries K, Kiss L, Ellsberg M, et al. What factors are associated with recent intimate partner violence? Findings from the WHO multi-country study on women's health and domestic violence. BMC Public Health. 2011:11(1):109.

68. Foran HM, O'Leary KD. Alcohol and intimate partner violence: a metaanalytic review. Clin Psychol Rev. 2008;28(7):1222-34.

69. Freisthler B, Needell B, Gruenewald PJ. Is the physical availability of alcohol and illicit drugs related to neighborhood rates of child maltreatment? Child Abuse Negl. 2005;29(9):1049-60.

70. Starmann E, Collumbien M, Kyegombe N, Devries K, Michau L, Musuya $\mathrm{T}$, et al. Exploring Couples' processes of change in the context of 
SASA!, a violence against women and HIV prevention intervention in Uganda. Prev Sci. 2017;18(2):233-44.

71. Speizer IS. Intimate partner violence attitudes and experience among women and men in Uganda. J Int Violence. 2009;25(7):1224-41.

\section{Publisher's Note}

Springer Nature remains neutral with regard to jurisdictional claims in published maps and institutional affiliations.

Ready to submit your research? Choose BMC and benefit from:

- fast, convenient online submission

- thorough peer review by experienced researchers in your field

- rapid publication on acceptance

- support for research data, including large and complex data types

- gold Open Access which fosters wider collaboration and increased citations

- maximum visibility for your research: over $100 \mathrm{M}$ website views per year

At $\mathrm{BMC}$, research is always in progress. 